\title{
Preliminary Thermal Design and Analysis of Lunar Lander for Night Survival
}

\author{
Tae-Yong Park $\mathbb{D},{ }^{1}$ Jang-Joon Lee, ${ }^{2}$ Jung-Hoon Kim, ${ }^{2}$ and Hyun-Ung Oh $\mathbb{D}^{1}$ \\ ${ }^{1}$ Space Technology Synthesis Laboratory, Department of Aerospace Engineering, Chosun University, 309, Pilmun-daero, Dong-gu, \\ Gwangju 61452, Republic of Korea \\ ${ }^{2}$ Korea Aerospace Research Institute (KARI), 169-84, Gwahak-ro, Yuseong-gu, Daejeon 34133, Republic of Korea
}

Correspondence should be addressed to Hyun-Ung Oh; ohu129@chosun.ac.kr

Received 3 July 2018; Revised 24 August 2018; Accepted 2 September 2018; Published 30 October 2018

Academic Editor: Angelo Cervone

Copyright $\odot 2018$ Tae-Yong Park et al. This is an open access article distributed under the Creative Commons Attribution License, which permits unrestricted use, distribution, and reproduction in any medium, provided the original work is properly cited.

A lunar lander is exposed to extreme lunar thermal environments with a nighttime of 14.75 earth days. Thus, a proper thermal design is an important task to guarantee a successful lunar mission. This paper describes a preliminary thermal design and analysis results of a lunar lander to ensure its survivability during lunar night. The effectiveness of the thermal designs of a lunar lander with various thermal hardwares was numerically investigated according to the landing candidate areas to determine which design is the most feasible for night survival. In addition, we analyzed the mechanical safety of the solder joint of electronic components in accordance with the operating temperature range, because it is an important factor for reducing the system power budget during night survival.

\section{Introduction}

After lunar exploration missions have been initiated by competition between the USA and Soviet Union in the field of space technology development in the 1960s, numerous lunar lander missions have been undertaken for the purposes of scientific research and excavation of resources such as water and rare-earth elements [1-4]. Recently, universities and institutes around the world have also been participating in challenging lunar missions using pico-class miniaturized CubeSats or micro-rovers as a cost-effective means of education and technology verification [5-7].

Lunar landers are exposed to severe lunar thermal environments with a daily surface temperature difference of approximately $300^{\circ} \mathrm{C}$ owing to the absence of atmosphere to absorb heat energy and the high absorptivity and emissivity values of lunar regolith [8]. The low thermal conductivity and thermal capacity of the lunar regolith also contribute to the surface temperature difference. In addition, lunar missions are rendered more challenging by the extremely cold lunar nighttime of approximately 14.75 earth days without sunlight. To ensure successful lunar lander missions, a proper thermal design is important to maintain the onboard equipment within their acceptable temperature thresholds under a harsh lunar thermal environment, especially during the nighttime.

For the thermal design of a lunar lander, radiator surfaces coated with thermal coatings or second-surface mirrors (SSMs) are employed to reject the waste heat produced by on-board equipment into space and to reduce the absorption of external solar fluxes [9]. The rest of the external surfaces are covered with multilayer insulation (MLI) to protect the lander from incident environmental heat fluxes. Excessive heat loss through the radiator during the nonoperating state of equipment is compensated by a heater. An electrical-resistance-type heater is suitable for this purpose and has been widely used in earth- or lunar-orbiting satellites experiencing an eclipse period ranging from a few minutes to hours. However, the use of an electric heater as a primary heat source in a lunar lander might lead to the excessive weight and size of electrical power systems including the solar arrays and batteries required to survive during 14.75 earth days of nighttime [10]. 
Therefore, in previous lunar missions, a radioisotope thermoelectric generator (RTG) has been used to reduce the reliance on solar energy for electrical power generation [11-13]. An RTG is an electrical power generator that uses a thermoelectric device to convert heat energy produced from the decay of a radioisotope into electrical energy via the Seebeck effect. The main advantages of RTGs are the stability of power generation regardless of day and night periods and a long lifetime achieved by the use of a radioisotope with a half-life ranging from a few years to several decades. The application of RTGs to a lunar lander enhances its survivability and extends the mission during nighttime. In the Apollo $12,14,15,16$, and 17 missions, systems for nuclear auxiliary power-27 (SNAP-27) RTGs were employed to supply power to Apollo Lunar Surface Experiment Packages (ALSEPs) [11]. They had reliably functioned beyond their mission design lifetime of one year. In addition to the lunar missions, numerous interplanetary exploration missions have also used several types of RTGs and demonstrated their reliability $[12,13]$. However, these RTGs are still less advantageous for night survival of a lunar lander because of their large weight, low energy conversion efficiency of less than $10 \%$, and inefficient process of converting heat into electrical power and thereafter using it to operate an electric heater [9]. The high development cost, safety assurance, and political criticality related to the use of a radioisotope material, such as plutonium-238, also make it difficult to apply RTGs in space programs.

A radioisotope heater unit (RHU) has been developed to overcome the disadvantages of RTGs [10, 14, 15]. An RHU directly provides the heat energy of a decaying radioisotope to on-board equipment without consuming electrical power like an electric heater. In addition, the RHU does not perform the energy conversion process, and hence, it is much simpler and smaller than the conventional RTGs. The NASA jet propulsion laboratory has developed a light-weight RHU (LWRHU) for space applications [14]. A plutonium-238 oxide $\left({ }^{238} \mathrm{PuO}_{2}\right)$ pellet capable of producing thermal power of $1 \mathrm{~W}$ is contained in the cylindrical holder, which consists of encapsulation clad, insulator, and aeroshell. The dimensions of the LWRHU are a diameter of $26 \mathrm{~mm}$ and height of $32 \mathrm{~mm}$ with a mass of approximately $40 \mathrm{~g}$ per unit, and thus, it is easily applicable to dispersed locations on the spacecraft. In addition, a 238PuO2-based RHU called Angel with the thermal power of $8.5 \mathrm{~W}$ has been developed and employed in the Russian Mars explorer Mars 96 [15].

In addition to the radioisotope-based technologies, Okishio et al. [16] proposed a lunar overnight method based on passive thermal control using the characteristics of regolith whose temperature remains constant at a depth of approximately $0.3 \mathrm{~m}$ or more. Aluminum cantilever rods, which are installed vertically on the bottom side of a lunar lander, penetrate into the subsurface of the regolith when the lander is landed on the moon for heat exchange between the lander and the constant-temperature layer of the regolith. This makes it possible to use the regolith as a heat sink during daytime, while using it as a heat source for nighttime survival. The effectiveness of this method was numerically and experimentally validated under a simulated lunar thermal vacuum environment. However, this method involves additional mechanisms and actuators to penetrate the rods into the regolith, thus rendering it difficult and complex to apply this method to a lunar lander. The lack of space heritage is also one of the limitations of its application to an actual lunar mission.

Therefore, an RHU might be more suitable for the night survival of a lunar lander as compared with the previous technologies in terms of the system simplicity and reliability. However, the thermal control of a lunar lander with the use of an RHU is still an issue because the continuous heat generation of an RHU during daytime would lead to overheating of the on-board equipment. The increase in radiator area to prevent overheating leads to a larger number of RHUs for nighttime, which consequently becomes a vicious cycle of thermal design. Therefore, a more effective thermal design is required to ensure the temperature stability of a lunar lander during both day and night periods.

One of the potential risks of a lunar lander is the fatigue failure of a solder joint owing to the accumulated thermal stresses induced by a mismatch between the coefficients of thermal expansion of the printed circuit board (PCB) and electronic package. For example, a malfunction of the system mission timer caused by a cracked solder joint owing to thermal stress was reported during the Apollo 11 mission [17]. This indicates that a proper thermal design is essential not only for thermal control but also for ensuring mechanical reliability of the solder joint. In this regard, the minimum operating temperature of electronic equipment during nighttime is an important factor because it determines the temperature variation in electronic components, which affects the level of thermal stress on the solder joint. Thus, the mechanical reliability of the solder joint can be enhanced as the minimum operating temperature is increased to reduce the temperature variation. However, this also leads to an increase in the number of RHUs required for night survival. Therefore, an optimal operating temperature to minimize the power and mass budgets of a lunar lander guaranteeing the mechanical reliability of the solder joint should be investigated considering the thermal cycling of a lunar lander during its mission lifetime. However, this has not yet been investigated in previous studies.

In this study, we performed preliminary thermal design and analysis of a lunar lander for ensuring survivability under the lunar thermal environment, especially during the nighttime. A thermal model that can simulate the lunar surface temperature was constructed and validated by comparison with Apollo 17 data, by using commercial thermal modeling and analysis tools of Thermal Desktop [18] and Systems Improve Numerical Differencing Analyzer/Fluid Integrator (SINDA/FLUINT) [19]. Based on the thermal model, the effectiveness of the thermal designs of a lunar lander with various thermal hardwares (H/Ws) was investigated through numerical thermal analysis according to landing candidate areas in terms of the required power of RHU for night survival. Consequently, we identified the most feasible thermal design for the night survival of a lunar lander. In addition, we also analyzed the mechanical reliability of a solder joint of electronic components in accordance with 
TABLE 1: Thermal environment conditions on the lunar surface [8].

\begin{tabular}{|c|c|c|c|c|}
\hline Parameter & & & Daytime & Nighttime \\
\hline Solar flux $\left(\mathrm{W} / \mathrm{m}^{2}\right)$ & & & 1414 (subsolar peak) & 0 \\
\hline Albedo [21] & & & $0.076-0.297$ & 0 \\
\hline Planetary IR flux $\left(\mathrm{W} / \mathrm{m}^{2}\right)$ & & & 1314 (subsolar peak) & 5.2 \\
\hline \multicolumn{3}{|l|}{ Imposed heat flow $\left(\mathrm{W} / \mathrm{m}^{2}\right)[22]$} & \multicolumn{2}{|c|}{0.031} \\
\hline \multicolumn{3}{|c|}{ Equator $\left(0^{\circ}\right)$} & 117 & -178 \\
\hline \multirow[t]{2}{*}{ Lunar surface temperature $\left({ }^{\circ} \mathrm{C}\right)[20]$} & \multirow{2}{*}{ Pole $\left(89^{\circ}\right)$} & Summer & -93 & \multirow[t]{2}{*}{-145} \\
\hline & & Winter & -2 & \\
\hline
\end{tabular}

the operating temperature range determined by the number of RHU because it is important for reducing the system power and mass budgets of the lander during nighttime.

\section{Construction of Thermal Model of Lunar Regolith}

2.1. Overview of Lunar Thermal Environment. The thermal environmental conditions on the lunar surface include incident solar flux, albedo, planetary infrared (IR) flux, and imposed heat flow in the subsurface, as summarized in Table 1 [8]. The table also lists the maximum and minimum temperatures of the lunar surface according to different latitudes, which have been measured by a lunar reconnaissance orbiter [20]. The temperature of the lunar surface at the equator (latitude $0^{\circ}$ ) ranges from 117 to $-178^{\circ} \mathrm{C}$ owing to the absence of an atmosphere, the low thermal conductivity and capacity, and the high absorptivity and emissivity values. In addition, the planetary IR flux reaches the maximum value of $1314 \mathrm{~W} / \mathrm{m}^{2}$ with respect to the incoming solar flux of maximum $1414 \mathrm{~W} / \mathrm{m}^{2}$. This IR flux intensity is more severe than that of the Earth's surface or on-orbit environment $[8,9]$.

In addition, the lunar surface is distinguished into different regions such as a highland and a lunar mare. In general, a highland is brighter than a lunar mare, and it also has higher albedo. The albedo value ranges from 0.076 to 0.297 according to the brightness of different regions [21]. These environmental conditions indicate that the different latitudes and different regions of landing area should be considered in the thermal design of a lunar lander. Therefore, in this study, we determined five landing candidate areas as shown in Figure 1 . Here, areas 1 and 2 correspond to a highland and lunar mare at the equator with the latitude of $0^{\circ}$, respectively. Areas 3 and 4 correspond to a highland and lunar mare at the mid-latitude of $45^{\circ}$, respectively, and area 5 corresponds to the highland of a polar region with the latitude of $88.5^{\circ}$ under the assumption that the incidence angle between the sun and lunar surface is $1.5^{\circ}$ and the nighttime lasts for 14.75 days.

2.2. Thermal Model of Lunar Regolith. Prior to the preliminary thermal design and analysis of the lunar lander, a reliable thermal model of the lunar regolith is essential to effectively simulate the surface temperature variation with the moon's rotation. In a previous study, Christie et al. [22] constructed a thermal model of the regolith using a commercial software called thermal analyzer system (TAS) and

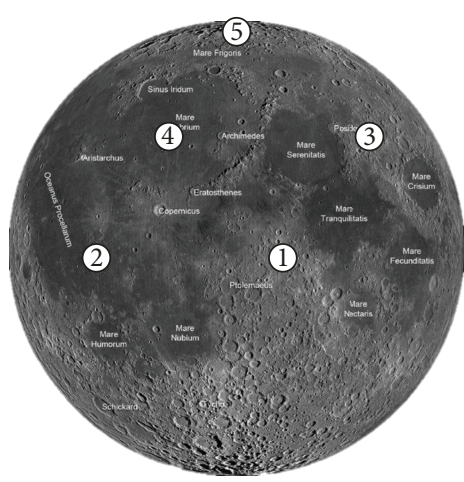

FIGURE 1: Landing candidate areas of a lunar lander [29].

validated it by comparing the analyzed surface temperature with that measured by the Apollo 17 mission. As the TAS cannot simulate the variation in the sun incidence angle according to the moon's rotation, the authors simulated it by changing the flux magnitude with a sine function. However, the thermal analysis of a lunar lander using this method suffers from a limitation because it cannot effectively simulate the continuously varying orientation of the sun with respect to each panel of the lander.

To overcome the limitations of the aforementioned approach, thermal analysis was performed by using the SINDA/FLUINT and the CAD-based geometric interface of Thermal Desktop to construct a thermal mathematical model (TMM). The TMM and the output of a RadCAD, which is a module that calculates radiation exchange factors and environmental heating rates based on a Monte Carlo ray-tracing algorithm, are used as the input of SINDA/ FLUINT. Therefore, by using the SINDA/FLUINT with the RadCAD, the variation in the sun incidence angle according to the moon's rotation and the latitude of the landing area can be effectively simulated, in contrast to the TAS.

Figure 2 shows a TMM of the lunar regolith constructed using the Thermal Desktop. The regolith consists of dust and underlying soil layers, which are modeled using two separate brick elements to reflect the variation in their material properties. Each layer has the area of $100 \mathrm{~m} \times 100 \mathrm{~m}$ where the nodes are placed in a $10 \mathrm{~m} \times 10 \mathrm{~m}$ grid along the in-plane directions of the $X$ - and $Y$-axes. However, the nodes in the center area of $9.9 \mathrm{~m} \times 9.9 \mathrm{~m}$ are placed in a finer manner in a $0.3 \mathrm{~m} \times 0.3 \mathrm{~m}$ grid to simulate a shadow effect owing to 


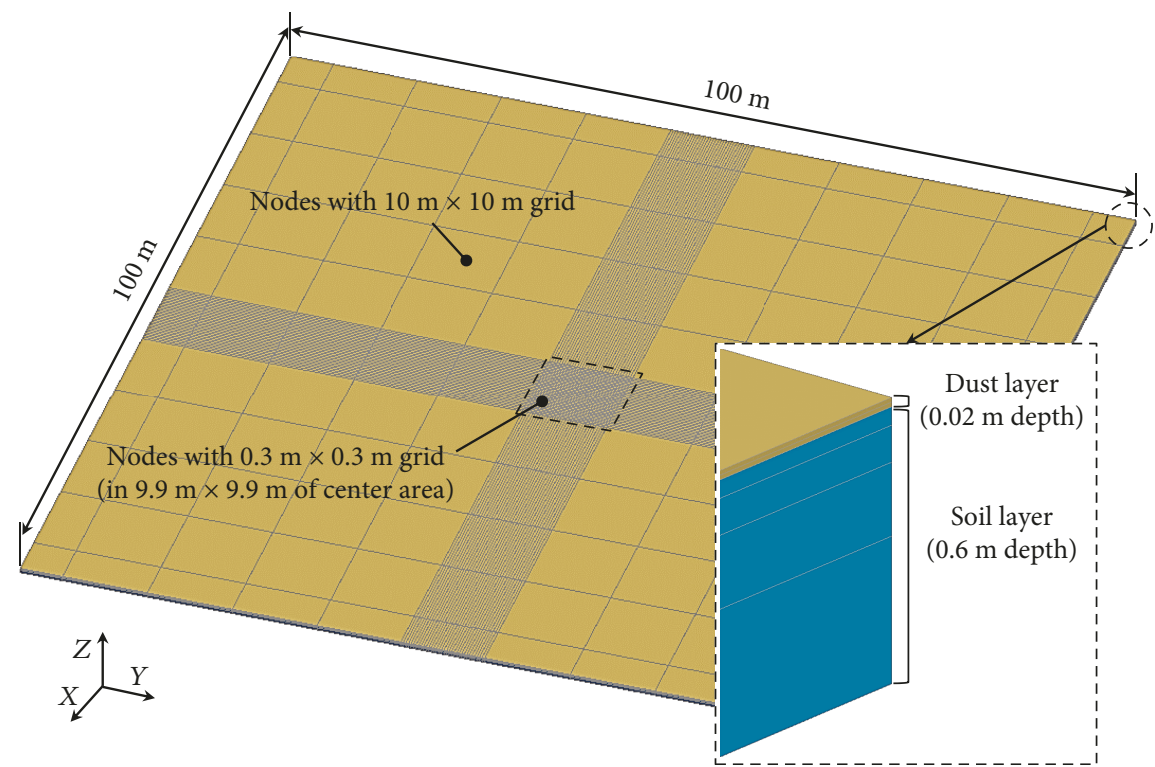

FIGURE 2: TMM of the lunar regolith.

TABLE 2: Material properties applied to thermal model [22].

\begin{tabular}{|c|c|c|c|}
\hline Parameter & & Highland & Lunar mare \\
\hline \multirow{3}{*}{ Thermo-optical properties } & Solar absorptivity [21] & 0.703 & 0.924 \\
\hline & Specularity (albedo) [21] & 0.297 & 0.076 \\
\hline & IR emissivity & \multicolumn{2}{|c|}{0.97} \\
\hline \multirow{3}{*}{ Thermo-physical properties } & Thermal conductivity $(\mathrm{W} / \mathrm{m} / \mathrm{K})$ & \multicolumn{2}{|c|}{ Eq. (1)/Eq. (2) (dust/soil) } \\
\hline & Density $\left(\mathrm{kg} / \mathrm{m}^{3}\right)$ & \multicolumn{2}{|c|}{ 1000/2000 (dust/soil) } \\
\hline & Specific heat $(J / k g / K)$ & \multicolumn{2}{|c|}{1050} \\
\hline
\end{tabular}

the presence of the lunar lander. The depths of the soil and dust layers in the out-of-plane direction of the $Z$-axis are $0.02 \mathrm{~m}$ and $0.6 \mathrm{~m}$, respectively. The total number of nodes used in the model is 9090 .

After creating the geometry of the regolith, the material properties summarized in Table 2 were applied to each layer. The thermo-optical properties were applied only to the $+\mathrm{Z}$ side of the dust layer where the radiation heat exchange with the outer thermal environment occurred. The thermophysical properties such as density and specific heat were applied as fixed values, but the thermal conductivity was applied as a temperature-dependent value because this is the most dominant factor in simulating the lunar surface temperature. The thermal conductivities of the dust and soil layers as a function of absolute temperature $T$ (kelvin) can be derived from the following empirical formulae $[23,24]$ :

$$
\begin{aligned}
& k_{\text {dust }}=9.22 \times 10^{-4} \times\left[1+1.48 \times\left(\frac{T}{350}\right)^{3}\right], \\
& k_{\text {soil }}=9.30 \times 10^{-3} \times\left[1+0.073 \times\left(\frac{T}{350}\right)^{3}\right] .
\end{aligned}
$$

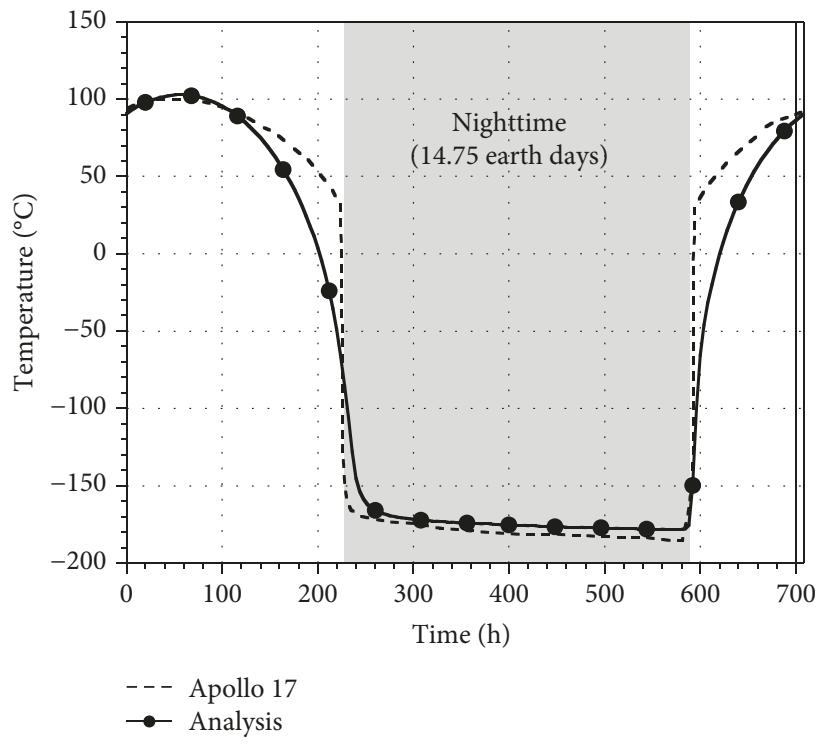

FIgURE 3: Comparison between the lunar surface temperatures of the analysis and Apollo 17 data. 


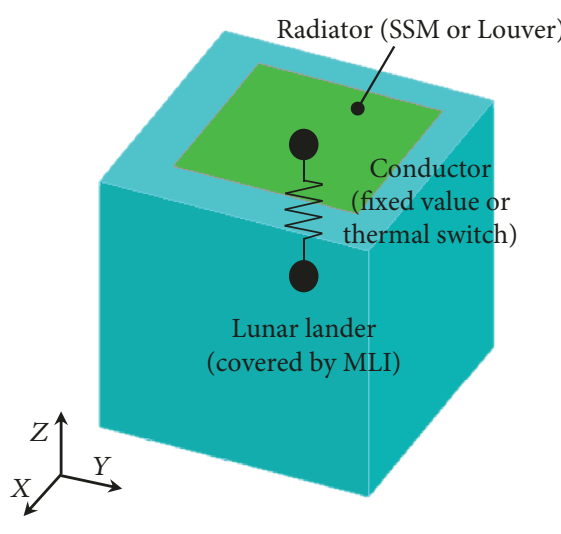

(a)

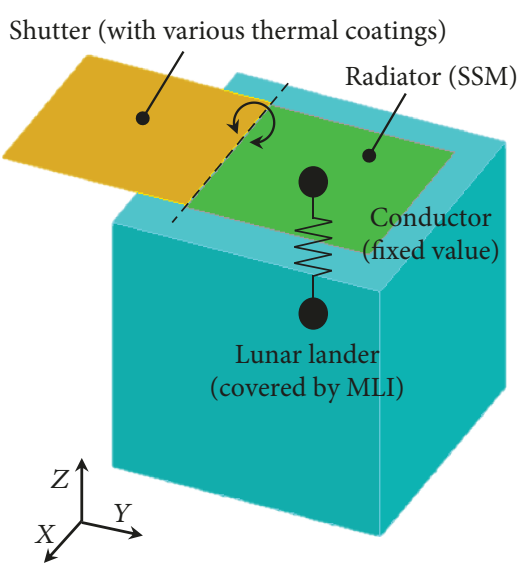

(b)

Figure 4: TMM of the lunar lander ((a) without shutter (b) with shutter).

In addition, the contact conductance between the dust and soil layers was simulated using a contactor. The contact conductance $h$ can be expressed as follows [25]:

$$
h=\frac{k_{\mathrm{eq}} A}{L},
$$

where $k_{\text {eq }}$ is the equivalent thermal conductivity of the dust and soil layers; $A$ and $L$ are the area and thickness, respectively, of a virtual interface layer between these layers, which was assumed to exist for calculating $h$. Through preliminary analysis, the value of $L$ was determined to be $0.01 \mathrm{~m}$. Thus, $k_{\text {eq }}$ can be calculated as follows [25]:

$$
k_{\text {eq }}=\frac{1}{\left(1 / k_{\text {dust }}\right)+\left(1 / k_{\text {soil }}\right)} .
$$

Finally, the imposed heat flow of $0.031 \mathrm{~W} / \mathrm{m}^{2}$ shown in Table 1 was applied as a heat load on the $-\mathrm{Z}$ side of the soil layer.

After the model construction, we performed thermal analysis to validate its effectiveness by comparing the surface temperature with that measured by the Apollo 17 mission. In the analysis, the absorptivity and albedo values of the lunar surface and the latitude were set to $0.87,0.13$, and $20^{\circ}$, respectively, to simulate the thermal environment of Apollo 17 landing area. Figure 3 shows the thermal analysis results of the time profile of the lunar surface temperature. The results obtained from the Apollo 17 mission [26] are also presented here for comparison. The figure shows that the analyzed surface temperature variation is similar to that obtained from the Apollo 17 data. The maximum and minimum surface temperatures are $102.5^{\circ} \mathrm{C}$ and $-178.5^{\circ} \mathrm{C}$, respectively, showing differences of $2.8^{\circ} \mathrm{C}$ and $6.7^{\circ} \mathrm{C}$, respectively, compared with those of the Apollo 17 mission. These results indicate that the thermal model constructed in this study effectively simulates the actual lunar surface temperature similar to the model proposed by Christie et al. [22]

\section{Numerical Investigations of Thermal Designs for Night Survival}

3.1. Overview of Thermal Analysis. To determine the most feasible thermal design for a lunar lander under the lunar thermal environment, a TMM of an example of lunar lander was created using Thermal Desktop as shown in Figure 4(a). As the critical system design of the lander has not yet been developed, the lander was simply modeled as a cube-shaped configuration with a single node at its center. It has a volume of $1 \mathrm{~m}^{3}$ and a mass of $500 \mathrm{~kg}$. An aluminum with the thermal conductivity of $167 \mathrm{~W} / \mathrm{m} / \mathrm{K}$ and specific heat of $980 \mathrm{~J} / \mathrm{kg} / \mathrm{K}$ was applied to the lander. The lander was located at the center of the regolith shown in Figure 2 at a height of $30 \mathrm{~cm}$ from the surface. This simplified form of the TMM is useful for evaluating the feasibility of the thermal design in the preliminary design phase of a lunar lander, when the detailed system configuration has not yet been established. The heat dissipations of the lander in daytime and nighttime are $120 \mathrm{~W}$ and $10 \mathrm{~W}$, respectively. The allowable temperature range of the lunar lander was assumed to be $-20^{\circ} \mathrm{C}$ to $50^{\circ} \mathrm{C}$ for evaluating the proposed thermal designs.

The thermal design of the lander shown in Figure 4(a) is composed of a radiator, MLI, and RHU. The radiator was installed on the $+\mathrm{Z}$ side of the lander to avoid surface contamination by lunar dust because it significantly degrades the performance of the radiator [9]. The thermal conduction between the radiator and lander was simulated by using a node-to-node conductor function in the software. The thermal conductance of the conductor was assumed to be $2000 \mathrm{~W} / \mathrm{m}^{2} / \mathrm{K}$. The MLI was simply modeled by applying the effective values of solar absorptivity and IR emissivity of 0.05 and 0.05 , respectively, on the surfaces of the lander instead of modeling it in detail. This is because the MLI modeling method is currently unimportant, because the focus of this study is to determine a more feasible thermal design for the nighttime survival of the lunar lander by comparing thermal designs with different thermal hardware. The RHU was applied as a heat load on the node of the lander. 
TABLe 3: Thermal properties of thermal control H/Ws.

\begin{tabular}{|c|c|c|}
\hline Thermal H/W & Parameter & Value \\
\hline \multirow{2}{*}{ SSM [9] } & Solar absorptivity & 0.1 \\
\hline & IR emissivity & 0.9 \\
\hline \multirow{3}{*}{ Louver [9] } & Solar absorptivity & 0.17 \\
\hline & Effective IR emissivity & 0.7 (open)/0.09 (close) \\
\hline & Blade open/close set point $\left({ }^{\circ} \mathrm{C}\right)$ & 0 \\
\hline \multirow{2}{*}{ Heat switch [9] } & Thermal conductance $\left(\mathrm{W} / \mathrm{m}^{2} / \mathrm{K}\right)$ & 6.58 (open)/640.66 (close) \\
\hline & Switch open/close set point $\left({ }^{\circ} \mathrm{C}\right)$ & 0 \\
\hline \multirow{3}{*}{ Shutter } & Radiator & SSM \\
\hline & Thermo-optical property (shutter) & Table 4 \\
\hline & Shutter panel open/close set point $\left({ }^{\circ} \mathrm{C}\right)$ & 0 \\
\hline
\end{tabular}

TABle 4: Thermo-optical properties of thermal coatings used to shutter.

\begin{tabular}{lccc}
\hline Thermal H/W & Solar absorptivity $(\alpha)$ & IR emissivity $(\varepsilon)$ & $\alpha / \varepsilon$ \\
\hline Black paint & 0.96 & 0.88 & 1.09 \\
Solar cell $(\mathrm{GaAs})$ & 0.92 & 0.95 & 1.08 \\
White paint & 0.246 & 0.924 & 0.27 \\
MLI & 0.05 & 0.05 & 1.0 \\
\hline
\end{tabular}

Table 3 lists the thermal properties of the thermal control hardwares selected for the lander. These H/Ws include an SSM, louver, heat switch, and shutter. The SSM used in this study has fixed values of solar absorptivity of 0.1 and IR emissivity of 0.9 . The louver is an active radiator whose emissivity value can be changed as the blades installed in front of the radiator surface are opened or closed by the actuator according to the temperature. The louver used in this study has the absorptivity of 0.17 , and its effective emissivity varies from 0.09 to 0.7 . The thermal conductivity of the heat switch can be changed by controlling the contact condition between the two separate surfaces according to the temperature. The thermal conductance values of the heat switch used in this study are $6.58 \mathrm{~W} / \mathrm{m}^{2} / \mathrm{K}$ and $640.66 \mathrm{~W} / \mathrm{m}^{2} / \mathrm{K}$ in open and close states, respectively. These values were applied to the conductor between the lander and the radiator shown in Figure 4(a). The shutter operates with a similar principle as the louver, but a shutter panel is driven to open or close the SSM radiator, as shown in Figure 4(b). In case of the shutter, thermal coatings with various optical properties summarized in Table 4 were applied to determine the most suitable coating for the thermal control of the lander. In the analysis, the open/close set points of the louver, heat switch, and shutter were set to $0^{\circ} \mathrm{C}$.

3.2. Thermal Analysis Results. Figure 5 shows the analyzed temperature profiles of the lunar lander with and without RHU during a lunar day of $708 \mathrm{~h}$ when an SSM radiator of area $0.4 \mathrm{~m}^{2}$ was applied. The figure shows that the temperature of the lander without RHU varies from $-110.6^{\circ} \mathrm{C}$ to $47.5^{\circ} \mathrm{C}$. The temperature is maintained above $-20^{\circ} \mathrm{C}$ by employing an RHU of $135 \mathrm{~W}$. However, this leads to an

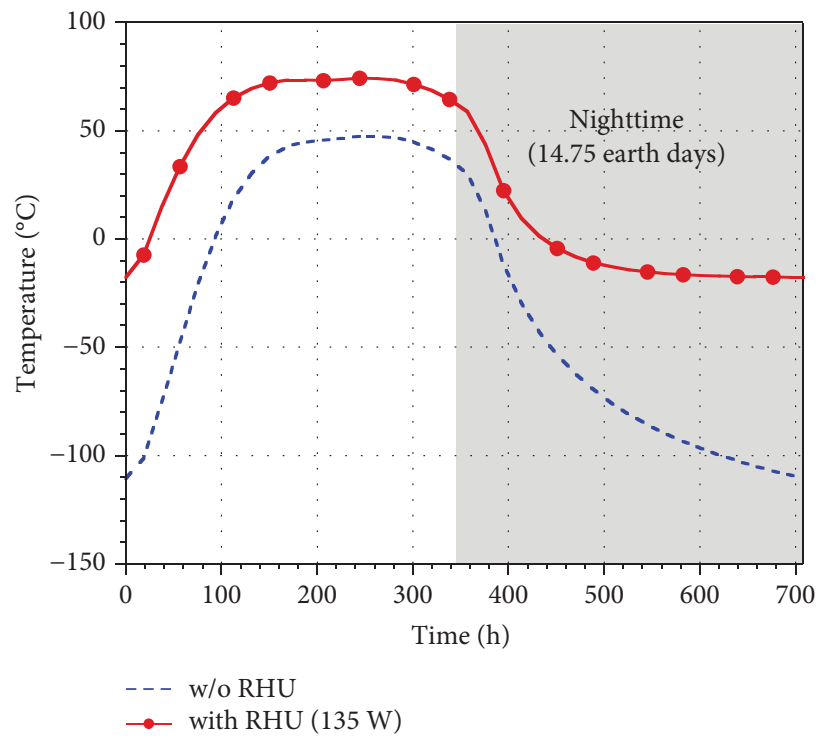

FIgURE 5: Temperature profiles of the lunar lander with and without RHU when applying SSM radiator.

increase in the maximum temperature during daytime up to $74^{\circ} \mathrm{C}$, which is $24^{\circ} \mathrm{C}$ higher than the allowable limit, owing to the continuous heat dissipation of RHU. The increase in radiator area to cool down the lander leads to an increase in the RHU power required for night survival, which could result in oversizing of the thermal control system of the lander.

Table 5 summarizes the analyzed maximum and minimum temperatures of the lander with and without an RHU and the required RHU power when the thermal H/Ws listed in Table 3 were applied. The table also summarizes the results obtained using the SSM radiator shown in Figure 5. Here, the radiator areas were fixed to $0.4 \mathrm{~m}^{2}$ in all cases for comparison with the SSM radiator. The results show that all the thermal designs require lower RHU power owing to the higher minimum temperature of the lander compared with that of the lander using the SSM radiator. The required RHU power is reduced to $107 \mathrm{~W}$ as the minimum temperature of the lander using the SSM radiator with a heat switch is increased by $7.6^{\circ} \mathrm{C}$ as compared with that of the lander using the SSM 
TABLE 5: Maximum and minimum temperatures and RHU power for a lunar lander with various thermal control H/Ws.

\begin{tabular}{lccccc}
\hline \multirow{2}{*}{ Thermal designs } & \multicolumn{3}{c}{ w/o RHU } & \multicolumn{3}{c}{ with RHU } \\
& $\begin{array}{c}T_{\max } \\
\left({ }^{\circ} \mathrm{C}\right)\end{array}$ & $\begin{array}{c}T_{\min } \\
\left({ }^{\circ} \mathrm{C}\right)\end{array}$ & $\begin{array}{c}T_{\max } \\
\left({ }^{\circ} \mathrm{C}\right)\end{array}$ & $\begin{array}{l}T_{\min } \\
\left({ }^{\circ} \mathrm{C}\right)\end{array}$ & $\begin{array}{c}\text { Req. RHU } \\
\text { power }(\mathrm{W})\end{array}$ \\
\hline SSM & 47.5 & -110.6 & 74 & -17.8 & 135 \\
SSM + heat switch & 47.8 & -103 & 69.7 & -17.9 & 107 \\
Louver & 64.8 & -103.5 & 88 & -18 & 115 \\
Louver + heat switch & 64.5 & -99 & 85 & -17.9 & 96 \\
Shutter & & & & & \\
$\quad$ White paint/solar cell & 47.3 & -95.9 & 65.3 & -19.8 & 87 \\
$\quad$ MLI/black paint & 46.9 & -73.3 & 57.2 & -19.4 & 48 \\
$\quad$ MLI/white paint & 47.1 & -73.3 & 57.2 & -19.5 & 48 \\
\hline
\end{tabular}

radiator only. In addition, a similar performance was observed in case of the louver. By applying the heat switch on the louver to maximize the thermal control performance, the minimum temperature is further increased to $-99^{\circ} \mathrm{C}$ and the RHU power is reduced to $96 \mathrm{~W}$. However, the use of the louver induces an increase in the maximum temperature of the lander with $\mathrm{RHU}$ to $88^{\circ} \mathrm{C}$ owing to its higher absorptivity and lower emissivity than the SSM.

For the evaluation of the shutter, white paint and solar cell were first applied on the external and internal sides of the shutter in closed state, respectively. This concept has been applied to the lunar rover Lunokhod [10]. The results in Table 5 indicate that the minimum temperature of the lander becomes $-95.9^{\circ} \mathrm{C}$ and the RHU power is reduced to $87 \mathrm{~W}$. This is because the solar cell with high absorptivity and emissivity absorbs the heat emitted by SSM and emits it to SSM again when they face each other as the shutter is closed during the night. However, heat loss through the white paint side of the shutter is unavoidable to some extent. To minimize the aforementioned heat loss, an MLI was applied on the external side of the shutter instead of the white paint. In this case, black or white paints were applied on the opposite sides. The analysis results shown in Figure 6 indicate that the temperature range of the lander using the shutter covered with MLI and black paint is $-73.3^{\circ} \mathrm{C}$ to $46.9^{\circ} \mathrm{C}$. This only requires an RHU power of $48 \mathrm{~W}$, which is at least 1.8 times lower than those of the other thermal designs. In addition, the shutter with MLI and white paint also showed a similar performance because of the thermal insulation by the MLI. These results indicate that the active thermal control strategy using a radiator with MLI shutter is most feasible for ensuring the survivability of the lander under an extreme lunar thermal environment with long nighttime among the proposed thermal designs.

Table 6 summarizes the area of the radiator with MLI shutter and RHU power to maintain the lander within the specified allowable temperature range $-20^{\circ} \mathrm{C}$ to $50^{\circ} \mathrm{C}$ in accordance with the landing candidate areas shown in Figure 1. The results indicate that the thermal design using a radiator with MLI shutter is effective at all the landing areas via optimization of the radiator area and RHU power. In particular, the lander is also expected to survive even at the polar region, which is much colder than the other areas, as long as

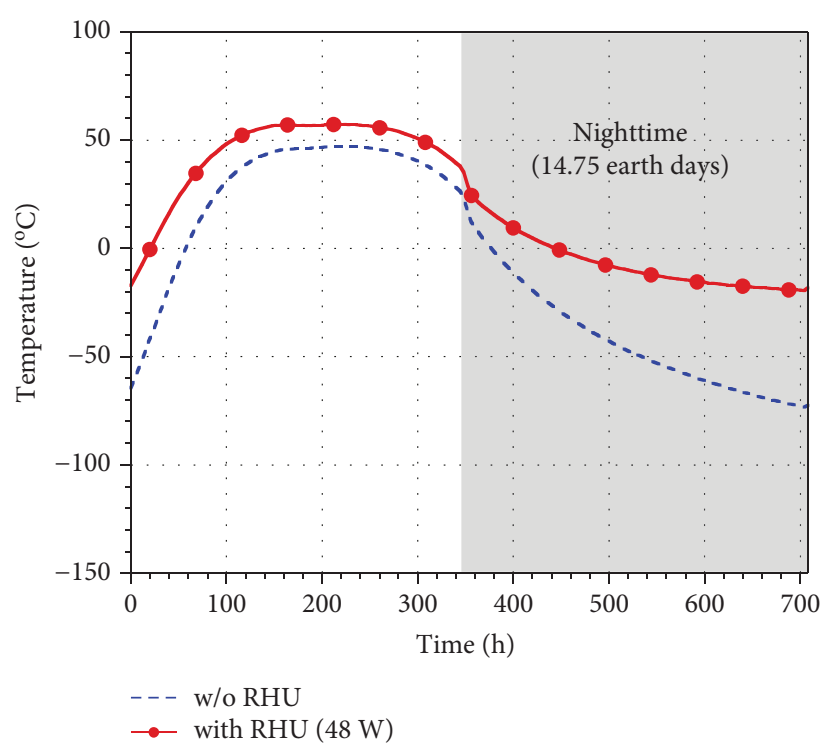

FIGURE 6: Temperature profiles of the lunar lander with and without RHU when applying a shutter with MLI and black paint on the SSM radiator.

TABLE 6: Optimal radiator area and RHU power for a lunar lander at various landing candidate areas.

\begin{tabular}{|c|c|c|c|c|}
\hline $\begin{array}{l}\text { Landing } \\
\text { candidate } \\
\text { area }\end{array}$ & Latitude & Region & $\begin{array}{c}\text { Required area } \\
\text { of radiator } \\
\left(\mathrm{m}^{2}\right)\end{array}$ & $\begin{array}{l}\text { Required } \\
\text { RHU power } \\
\text { (W) }\end{array}$ \\
\hline 1 & $0^{\circ}$ & Highland & 0.485 & 48 \\
\hline 2 & $0^{\circ}$ & $\begin{array}{c}\text { Lunar } \\
\text { mare }\end{array}$ & 0.495 & 48 \\
\hline 3 & $45^{\circ}$ & Highland & 0.479 & 48 \\
\hline 4 & $45^{\circ}$ & $\begin{array}{l}\text { Lunar } \\
\text { mare }\end{array}$ & 0.462 & 48 \\
\hline 5 & $88.5^{\circ}$ & Highland & 0.221 & 50 \\
\hline
\end{tabular}

sufficient power generation is possible in spite of the continuously changing length of nighttime according to the season.

In this study, we also investigated the influence of the lunar surface features on the thermal response of the lander. Accordingly, TMMs of the regolith with valley and boulder were constructed as shown in Figures 7(a) and 7(b), respectively. The valley shown in Figure $7(\mathrm{a})$ is $85.24 \mathrm{~m}$ in width and $21.8 \mathrm{~m}$ in depth. The lander was located near the valley at a distance of $2 \mathrm{~m}$. The boulder shown in Figure $7(\mathrm{~b})$ was assumed to be a hemisphere with a diameter of $4 \mathrm{~m}$ and was placed adjacent to the lander at a distance of $2 \mathrm{~m}$. The material properties of the boulder were obtained from the report by Vasavada [24]. Figure 8 shows the temperature profiles of the lander on the following surface features-flat surface, boulder, and valley. The results indicate that the temperature of the lander near the valley is slightly lower by less than $1.4^{\circ} \mathrm{C}$ (which is a negligible value) compared with that on the flat surface. However, the maximum temperature of the lander near the boulder becomes $52.7^{\circ} \mathrm{C}$, which is $4.2^{\circ} \mathrm{C}$ 


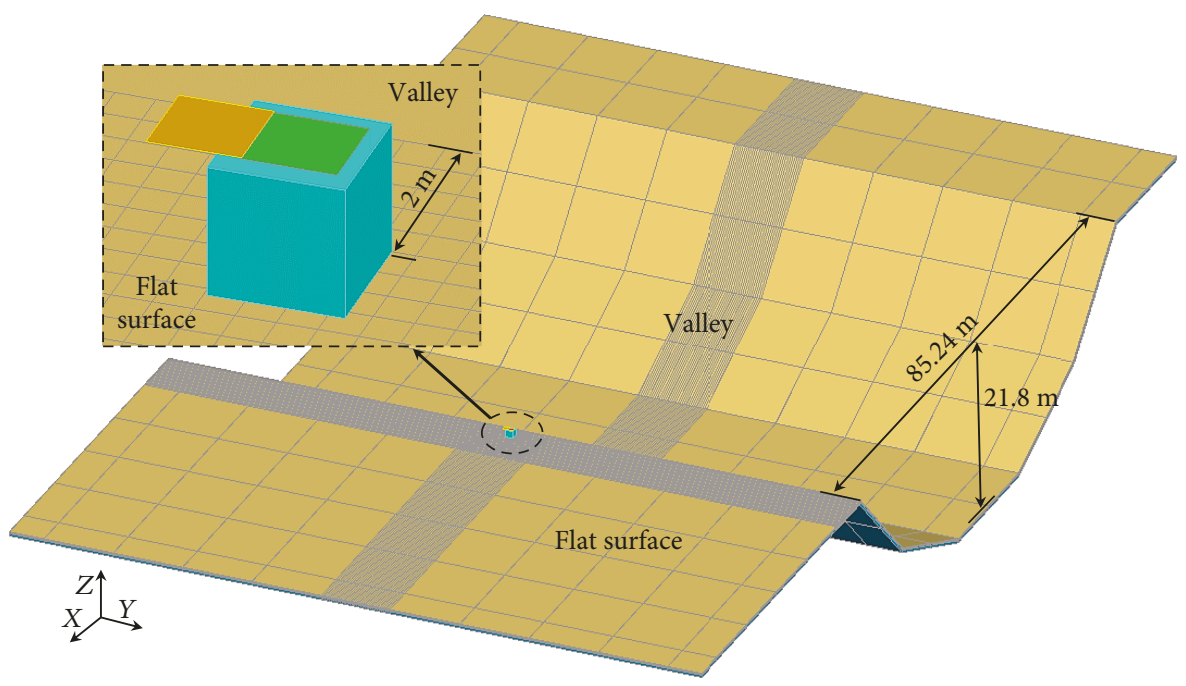

(a)

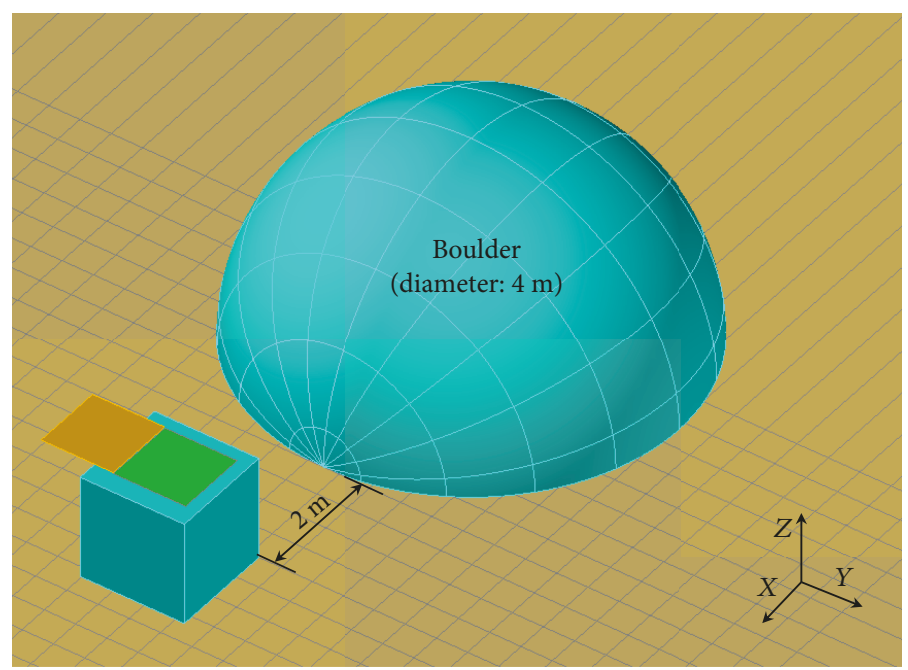

(b)

FIgURE 7: TMMs of the lunar lander exposed to various surface features of the regolith ((a) with valley and (b) with boulder).

higher than that on the flat surface owing to the IR heat flux emitted from the boulder in daytime although all the panels except the $+Z$ side are covered with the MLI. These results indicate that the influence of IR heat energy emitted by a boulder or mountain should be considered in the thermal design of the lander.

\section{Prediction of Mechanical Reliability of the Solder Joint}

The thermal analysis results indicate that the use of RHU could be a feasible solution for the night survival of the lander. However, the amount of required RHU power depends on the minimum operating temperature of the onboard electronic equipment. Figure 9 shows the required power and mass of the RHU according to the minimum operating temperature of the lander. This was estimated from the thermal analysis results shown in Table 6 under the assumption that an LWRHU [14] with the output power of
$1 \mathrm{~W}$ and mass of $40 \mathrm{~g}$ per unit was used for the lander. The figure shows that the power and mass of RHU increase as the minimum operating temperature is increased. For example, the power and mass of RHU are $30 \mathrm{~W}$ and $1.2 \mathrm{~kg}$, respectively, when the minimum operating temperature is $-40^{\circ} \mathrm{C}$. If the minimum operating temperature is increased to $0^{\circ} \mathrm{C}$, the power and mass increase to $65 \mathrm{~W}$ and $2.6 \mathrm{~kg}$, respectively, which are 2.17 times larger than the corresponding values at $-40^{\circ} \mathrm{C}$. In addition, this would also require a larger area of the radiator owing to the increase in the maximum temperature during daytime. However, the mechanical safety of a solder joint under lunar thermal environment might not be ensured owing to the increased temperature variation if the minimum operating temperature is too low. Thus, the optimal operating temperature should be determined for reducing the system power and mass budgets of the lander as much as possible.

Therefore, in this study, the mechanical reliability of a solder joint under a lunar thermal environment during a 


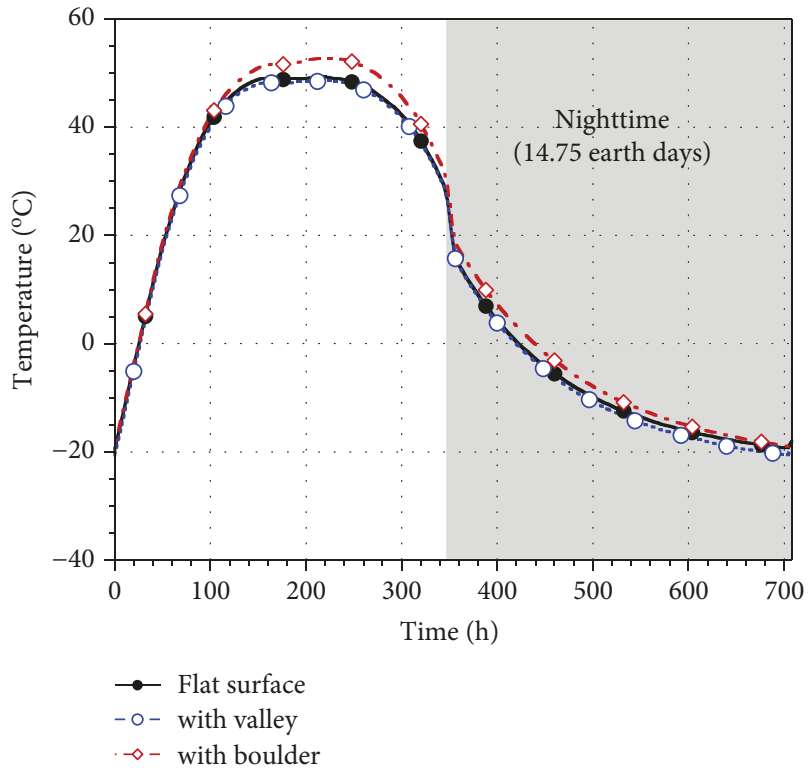

Figure 8: Temperature profile of the lunar lander exposed to the lunar surface features: flat surface, valley, and boulder.

mission life of 1 year was analyzed using a reliability and life prediction software called Sherlock [27]. In addition, the results were compared with those obtained under a low earth orbit (LEO). Sherlock has been widely used in various fields including automotive, electronics, defense, and aerospace engineering. This tool analyzes the reliability of electronic components based on the physics of failure combined with finite element analysis (FEA) for given environmental loads such as thermal cycling, vibration, and mechanical shock. In addition, this tool reduces the analysis time compared with the typical FEA tools as it automatically constructs a finite element model (FEM) of electronic PCB with various types of electronics packages based on the Gerber or ODB+ + files, which include information on the PCB layer, package, and solder joint. The reliability of the software program Sherlock has been validated in a previous study by Park et al. [28]. They performed the reliability prediction of a solder joint of plastic ball grid array (PBGA) package and thin-shrink small outline package (TSSOP) under launch random vibration using Sherlock. The results of the fatigue test of the PCB specimen under random vibration indicated that the difference in time-to-failure of the solder joint between the prediction and test is only $7.14 \%$.

Figure 10 shows the FEM of a PCB constructed using its Gerber file. A total of 28,598 elements and 116,585 nodes were used in the FEM. The FR-4 PCB has the dimensions of $121 \mathrm{~mm} \times 107.3 \mathrm{~mm} \times 1.65 \mathrm{~mm}$ and mass of 65.6 g. Five PBGA packages (U1, U4, U5, U6, and U9) with 324 solder balls and four TSSOPs (U2, U3, U7, and U8) with 48 gull-wing lead frames are applied to the PCB. The solder material used for the PCB assembly is Sn$\mathrm{Pb} 37$ with space heritage. Table 7 lists the specifications of the electronic packages.

For the reliability prediction of a solder joint under thermal environment, Sherlock uses the modified Engelmaier model. The in-plane shear strain on the solder joint, $\Delta \gamma$, is calculated as follows:

$$
\Delta \gamma=C \frac{L_{\mathrm{D}}}{h_{\mathrm{s}}} \Delta \alpha \Delta T
$$

where $C$ is a geometry-dependent constant, $L_{\mathrm{D}}$ is the diagonal distance from the neutral point of the package, $\Delta \alpha$ is the difference in thermal expansion between the die and package substrate or $\mathrm{PCB}$, and $\Delta T$ is the temperature difference of the thermal cycle. The calculated $\Delta \gamma$ is used to calculate the strain energy on the solder joint, $\Delta W$, as follows:

$$
\Delta W=0.5 \Delta \gamma \frac{F}{A_{s}},
$$

where $F$ is the shear force and $A_{\mathrm{s}}$ is the area of the solder joint. The calculated $\Delta W$ is used to predict the number of cycles to failure, $N_{\mathrm{f}}$, of the solder joint under thermal load by using (6) or (7) as follows with the solder materials Sn$\mathrm{Pb} 37$ or SAC305, respectively.

$$
\begin{aligned}
& N_{\mathrm{f}}=(0.0006061 \Delta W)^{-1}, \\
& N_{\mathrm{f}}=(0.0019 \Delta W)^{-1},
\end{aligned}
$$

Figures 11(a) and 11(b) show the time histories of failure probability of the U5 and U2 packages exposed to the lunar thermal environment for 1 year according to the various operating temperature ranges when the maximum temperature is fixed at $50^{\circ} \mathrm{C}$. These results were obtained by applying 12 thermal cycles for 1 year considering the moon's rotation period of 29.75 days. The figures show that the failure probability of the packages exponentially increases as the minimum operating temperature is decreased because $\Delta \gamma$ acting on the solder joint is proportional to $\Delta T$, as shown in (5). The failure probability of the U5 package with the operating temperature range from $-40^{\circ} \mathrm{C}$ to $50^{\circ} \mathrm{C}$ becomes $2.85 \times 10^{-6} \%$ after 1 year, whereas it is only $1.11 \times 10^{-14} \%$ for the U2 package under the same conditions. This is because the TSSOP with gull-wing lead frames is more flexible with respect to the thermal deformation in the in-plane direction of $\mathrm{PCB}$ compared with the PBGA solder joints.

Figures 12 (a) and 12(b) show the analysis results of the $\mathrm{U} 5$ and U2 packages exposed to the thermal environment in LEO during 1 year under the same operating temperature ranges, for comparison with the results shown in Figure 11. In the analysis, 5400 thermal cycles expected in the LEO of altitude $600 \mathrm{~km}$ during a year were applied to the PCB. The figures show that the failure probability of the packages after 1 year is much higher than the failure probability of those exposed to the lunar environment. In particular, the failure probability of the U5 package reaches $19.8 \%$ after 1 year when the operating temperature range is from $-40^{\circ} \mathrm{C}$ to $50^{\circ} \mathrm{C}$, which is $7 \times 10^{6}$ times higher than the results shown in Figure 11(a).

Table 8 summarizes the results of failure probability of the solder joint after 1 year of exposure to the thermal environments on the moon or in the LEO. The results indicate 


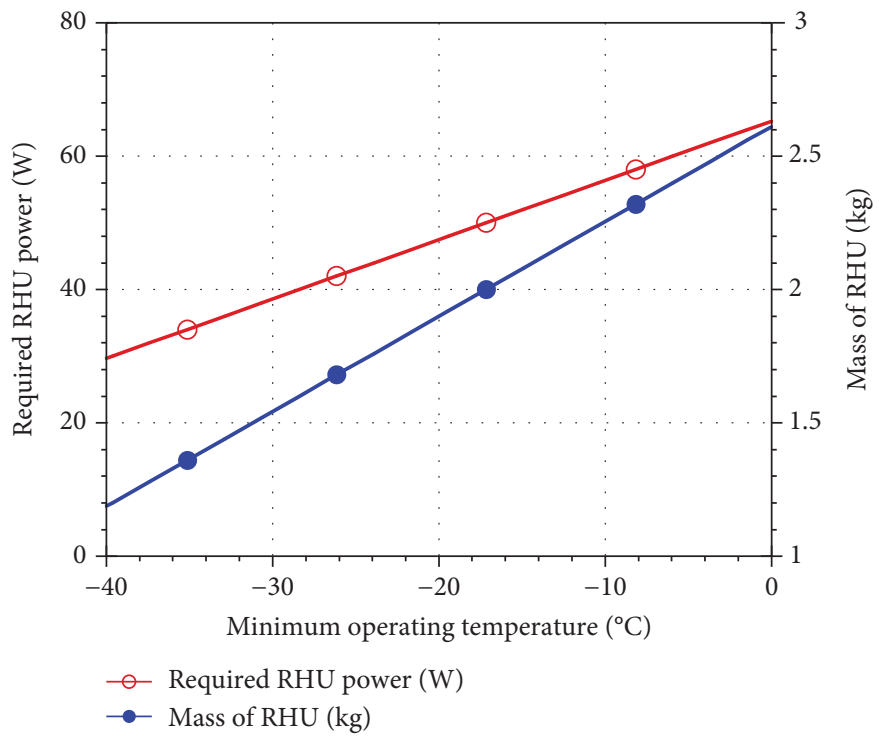

FIGURE 9: Temperatures of the lunar lander and mass of RHU according to the required power of RHU.

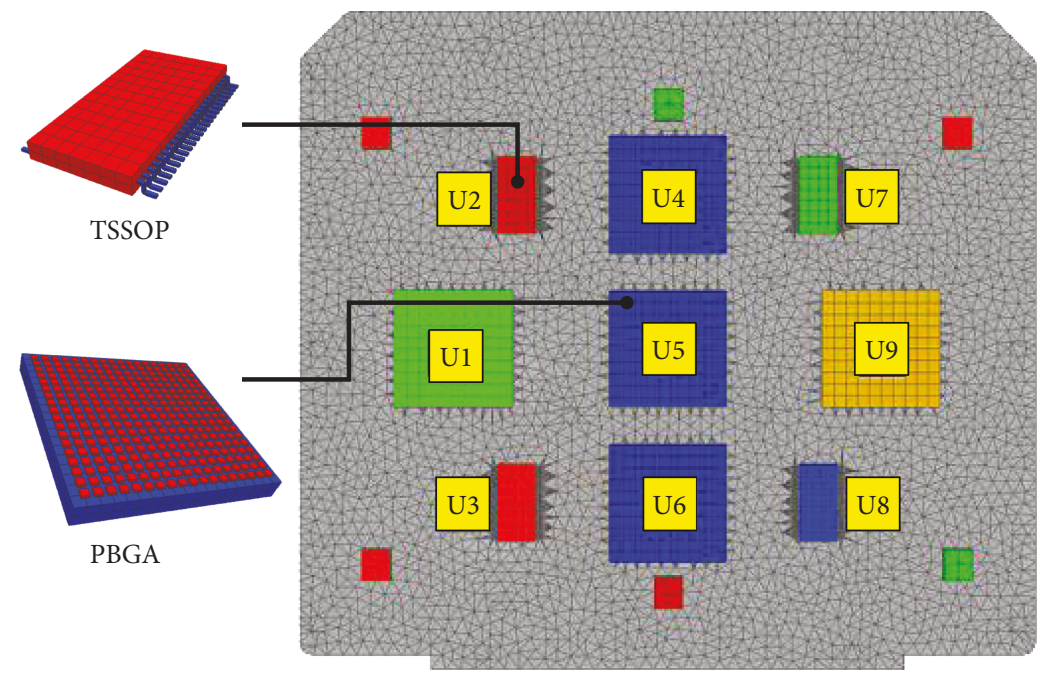

FIGURE 10: FEM of PCB with PBGA packages and TSSOPs.

TABLE 7: Specification of electronic packages.

\begin{tabular}{lcc}
\hline Package type & PBGA & TSSOP \\
\hline Configuration & 324 & 48 \\
Number of pins & $19 \times 19 \times 2.2$ & $12.5 \times 6.1 \times 1.2$ \\
Dimensions (mm) & 1.4 & 0.3 \\
Mass (g) & $\mathrm{Sn}-\mathrm{Pb} 37$ & $\mathrm{Sn}-\mathrm{Pb} 37$ \\
Solder material & - & $\mathrm{Copper}$ \\
Lead material & $\mathrm{U} 1, \mathrm{U} 4, \mathrm{U} 5, \mathrm{U} 6, \mathrm{U} 9$ & $\mathrm{U} 2, \mathrm{U} 3, \mathrm{U}, \mathrm{U} 8$ \\
Package no. &
\end{tabular}




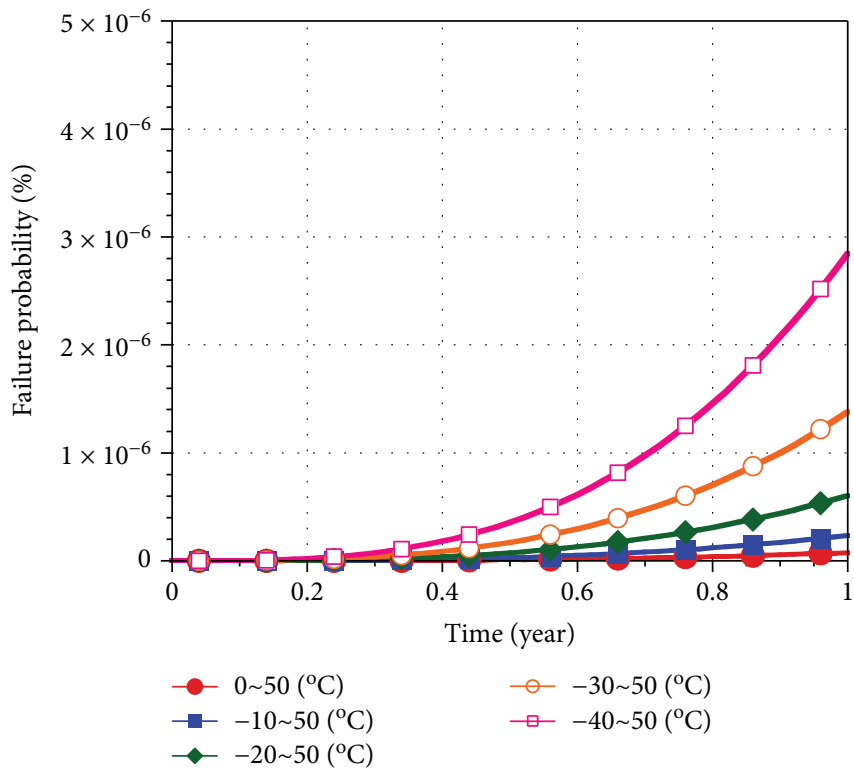

(a)

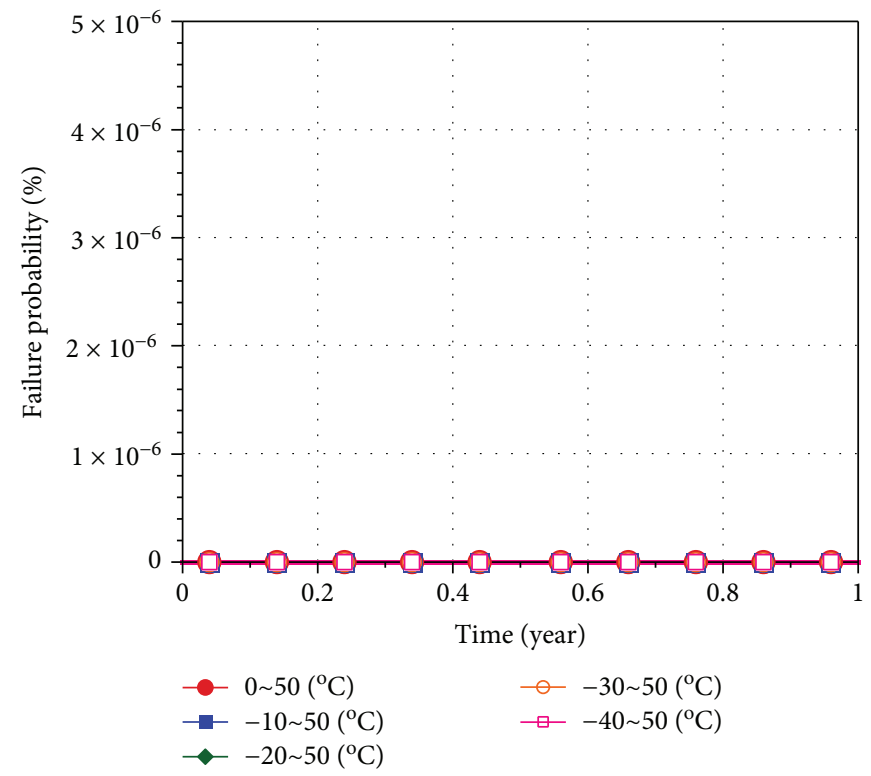

(b)

FIGURE 11: Time histories of the failure probabilities of U5 and U2 packages under lunar thermal environment ((a) U5 package and (b) U2 package).

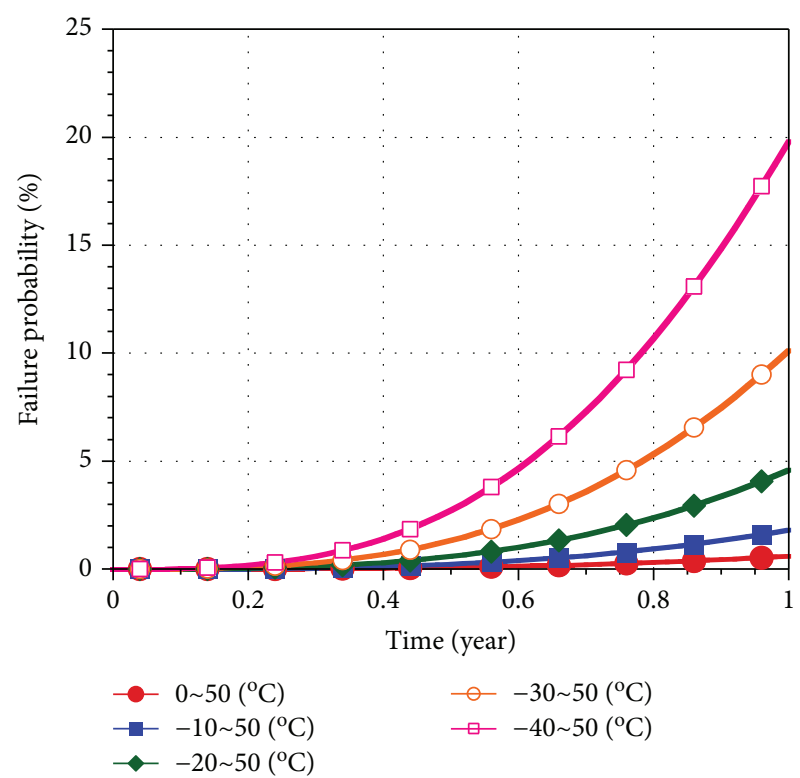

(a)

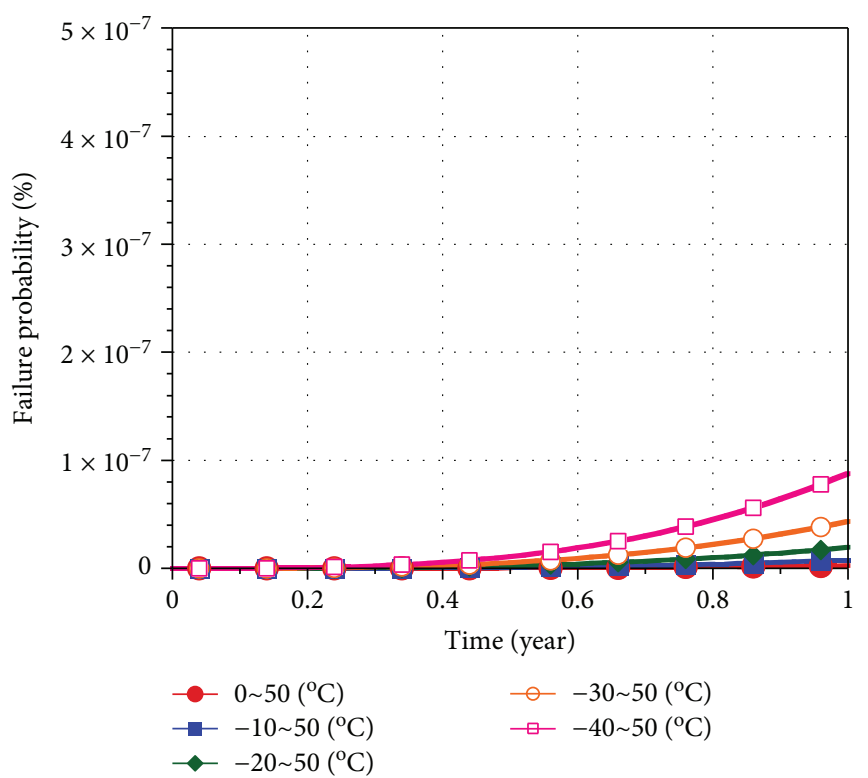

(b)

FIgURE 12: Time histories of the failure probabilities of U5 and U2 packages under LEO thermal environment ((a) U5 package and (b) U2 package).

that the minimum operating temperature for the on-board electronics of the LEO satellite should be sufficiently high to ensure the mechanical safety of the solder joint during an entire mission lifetime owing to the much larger number of thermal cycles compared with that in the lunar surface. However, in case of a lunar lander, the minimum operating temperature can be decreased to minimize the use of RHU for reducing the power and mass budgets of the lander because the failure probability of the solder joint remains an extremely lower value than that in the LEO environment. These analysis results demonstrate that the mechanical reliability of solder joints under the lunar thermal 
TABLE 8: Summary of predicted mechanical reliability of U5 and U2 solder joints under lunar and LEO thermal environments.

\begin{tabular}{|c|c|c|c|c|}
\hline \multirow{2}{*}{ Temperature range $\left({ }^{\circ} \mathrm{C}\right)$} & \multicolumn{2}{|c|}{ Lunar thermal environment } & \multicolumn{2}{|c|}{ LEO thermal environment } \\
\hline & U5 (\%) & U2 (\%) & U5 (\%) & U2 (\%) \\
\hline $0-50$ & $7.71 \times 10^{-8}$ & $3.00 \times 10^{-16}$ & 0.59 & $2.59 \times 10^{-8}$ \\
\hline$-10-50$ & $2.35 \times 10^{-7}$ & $9.15 \times 10^{-16}$ & 1.80 & $7.72 \times 10^{-8}$ \\
\hline$-20-50$ & $6.05 \times 10^{-7}$ & $2.36 \times 10^{-15}$ & 4.58 & $1.95 \times 10^{-7}$ \\
\hline$-30-50$ & $1.38 \times 10^{-6}$ & $5.37 \times 10^{-15}$ & 10.11 & $4.34 \times 10^{-7}$ \\
\hline$-40-50$ & $2.85 \times 10^{-6}$ & $1.11 \times 10^{-14}$ & 19.79 & $8.79 \times 10^{-7}$ \\
\hline
\end{tabular}

environment is ensured, even if the set point of the heater becomes close to the minimum allowable temperature limit of the lander's electronics.

\section{Conclusions}

In this study, we performed preliminary thermal design of a lunar lander to determine the most feasible design for ensuring survivability under harsh lunar thermal environments, especially the nighttime. To simulate the thermal environment conditions on the lunar surface, a reliable TMM of the lunar regolith was created and validated through the comparison of the analyzed surface temperature with that measured by Apollo 17. Based on the TMM of the regolith, thermal designs of the lander with various thermal control $\mathrm{H} / \mathrm{Ws}$ were numerically investigated in accordance with the various landing candidate areas. The analysis results indicate that the SSM radiator with a shutter covered with MLI is the most feasible way to maintain the temperature of the lander within the allowable range among the other thermal designs proposed in this study. In addition, the mechanical reliability of the solder joint was evaluated according to the various operating temperature ranges of the on-board electronic equipment of the lander. The results indicate that the failure probability remains an extremely low value even after 1 year of mission owing to the much smaller number of thermal cycles on the lunar surface. This indicates that the minimum operating temperature can be decreased as compared with that of the LEO satellites for saving the system power and mass budgets of the lander.

\section{Data Availability}

All the data supporting the results were shown in the paper and can be applicable from the corresponding author.

\section{Conflicts of Interest}

The authors declare that they have no competing interests.

\section{Acknowledgments}

This research was financially supported by the Korean Lunar Exploration Program of the National Research Foundation of Korea (NRF) funded by the Ministry of Science, ICT (MSIT) (NRF-2017M1A3A9043303).

\section{References}

[1] A. Young, The Apollo Lunar Samples: Collection Analysis and Results, Praxis, New York, NY, USA, 2017.

[2] B. Harvey, Soviet and Russian Lunar Exploration, Springer Science \& Business Media, New York, NY, USA, 2006.

[3] Z. Sun, Y. Jia, and H. Zhang, "Technological advancements and promotion roles of Chang'e-3 lunar probe mission," Science China Technological Sciences, vol. 56, no. 11, pp. 2702-2708, 2013.

[4] S. Tanaka, T. Mitani, H. Otake et al., "Present Status of the Lunar Lander Project SELENE-2," in 44th Lunar and Planetary Science Conference, p. 1838, The Woodlands, TX, USA, March 2013.

[5] T. Hashimoto, T. Yamada, J. Kikuchi, M. Otsuki, and T. Ikenaga, "Nano Moon Lander: OMOTENASHI," in 31th International Symposium on Space Technology and Science (ISTS), pp. 1-5, Ehime, Japan, 2017.

[6] R. Walker and M. Cross, "The European Student Moon Orbiter (ESMO): a lunar mission for education, outreach and science," Acta Astronautica, vol. 66, no. 7-8, pp. 1177-1188, 2010.

[7] W. D. Lakin and C. Brandon, "Landing a CubeSat payload on the moon: the Vermont Space Grant Lunar Lander Project," Design Principles and Practices: An International Journal, vol. 5, no. 3, pp. 79-88, 2011.

[8] B. M. French, G. Heiken, D. Vaniman, and J. Schmitt, Lunar Sourcebook: a User's Guide to the Moon, CUP Archive, Texas, USA, 1991.

[9] D. G. Gilmore, Spacecraft Thermal Control Handbook, Volume 1: Fundamental Technologies, The Aerospace Corporation, El Segundo, CA, USA, 2nd edition, 2002.

[10] S. Ulamec, J. Biele, and E. Trollope, "How to survive a lunar night," Planetary and Space Science, vol. 58, no. 14-15, pp. 1985-1995, 2010.

[11] G. R. Schmidt, T. J. Sutliff, and L. A. Dudzinski, "Radioisotope power: a key technology for deep space exploration," in 6th International Energy Conversion Engineering Conference (IECEC), pp. 419-456, Cleveland, OH, USA, July 2011.

[12] R. R. Furlong and E. J. Wahlquist, "U.S. space missions using radioisotope power systems," Nuclear News, vol. 42, pp. 26-34, 1999.

[13] G. L. Bennett, "A look at the soviet space nuclear power program," in Proceedings of the 24th Intersociety Energy Conversion Engineering Conference, pp. 1187-1195, Washington, DC, USA, August 1989.

[14] R. E. Tate, "Light weight radioisotope heater unit (LWRHU): a technical description of the reference design," Los Alamos National Laboratory, LA-9078-MS, 1982. 
[15] L. Summerer, "Technical aspects of space nuclear power sources," European Space Agency, ACT-RPT-2327-RHU, 2006.

[16] S. Okishio, H. Nagano, and H. Ogawa, "A proposal and verification of the lunar overnight method by promoting the heat exchange with regolith," Applied Thermal Engineering, vol. 91, pp. 1176-1186, 2015.

[17] Manned Spacecraft Center, "Apollo 11 Mission Report," NASA Scientific and Technical Information Office, 1971.

[18] Thermal Desktop User's Manual, Ver 5.8, C \& R Technologies, Inc., Boulder, CO, USA, 2017.

[19] SINDA/FLUINT User's Manual, Ver 5.8, C \& R Technologies, Inc., Boulder, CO, USA, 2015.

[20] D. A. Paige, M. C. Foote, B. T. Greenhagen et al., “The Lunar Reconnaissance Orbiter Diviner Lunar Radiometer Experiment," Space Science Reviews, vol. 150, no. 1-4, pp. 125-160, 2010.

[21] P. B. Hager, "Dynamic thermal modeling for moving objects on the moon," Dissertation, Technical University of Munich (TUM), Germany, 2013.

[22] R. J. Christie, D. W. Plachta, and M. M. Hasan, “Transient thermal model and analysis of the lunar surface and regolith for cryogenic fluid storage," NASA/TM-2008-215300, 2007.

[23] C. J. Cremers and R. C. Birkebak, "Thermal conductivity of fines from Apollo 12," Proceedings of the Lunar Science Conference, vol. 2, pp. 2311-2315, 1971.

[24] A. R. Vasavada, D. A. Paige, and S. E. Wood, "Near-surface temperatures on mercury and the moon and the stability of polar ice deposits," Icarus, vol. 141, no. 2, pp. 179-193, 1999.

[25] A. F. Mills, Basic Heat and Mass Transfer, Prentice Hall, Upper Saddle River, NY, USA, 2nd edition, 1999.

[26] M. G. Langseth Jr, S. J. Keihm, and J. L. Chute Jr, "Heat flow experiment," Apollo 17: Preliminary Science Report, NASA SP-330, Washington, DC, USA, 1973.

[27] J. McLeish and N. Blattau, "CAE apps for physics of failure reliability \& durability simulations," in 2014 Reliability and Maintainability Symposium, pp. 1-6, Colorado Springs, CO, USA, January 2014.

[28] T. Y. Park, J. C. Park, and H. U. Oh, "Evaluation of structural design methodologies for predicting mechanical reliability of solder joint of BGA and TSSOP under launch random vibration excitation," International Journal of Fatigue, vol. 114, pp. 206-216, 2018.

[29] https://cseligman.com/text/moons/moonmap.htm. 


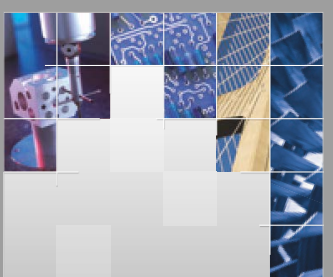

\section{Enfincering}
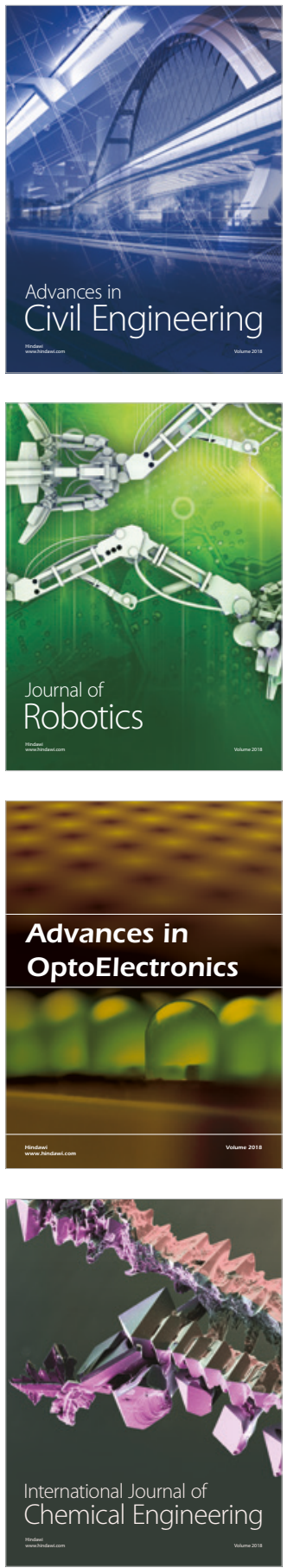

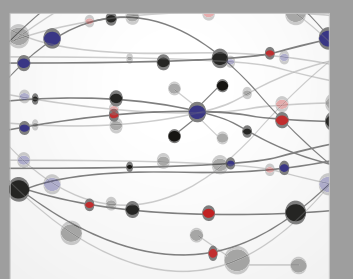

\section{Rotating \\ Machinery}

The Scientific World Journal

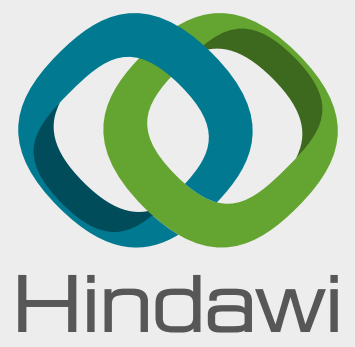

Submit your manuscripts at

www.hindawi.com
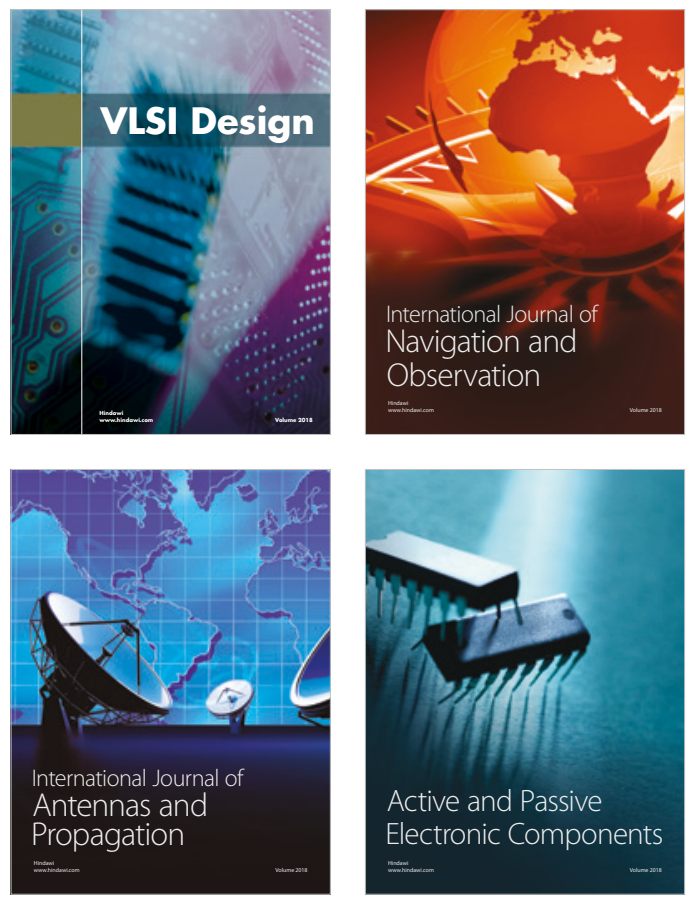
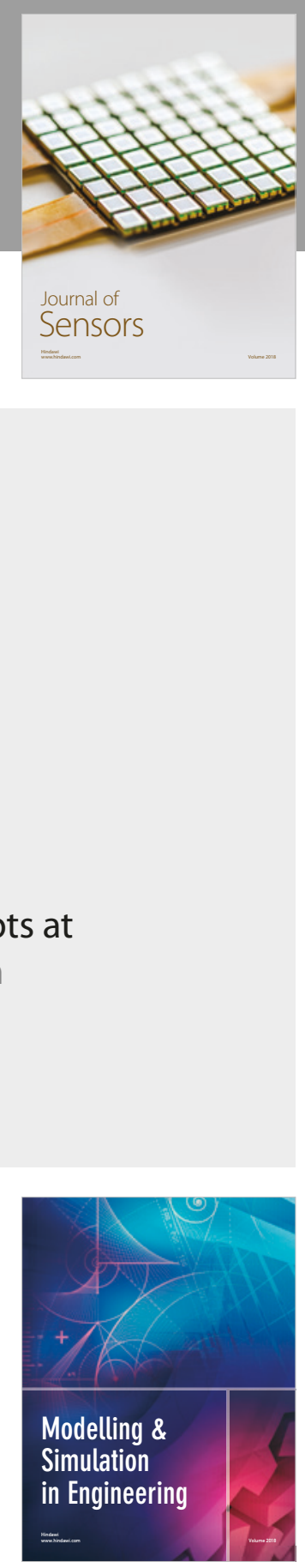

\section{Advances \\ Multimedia}
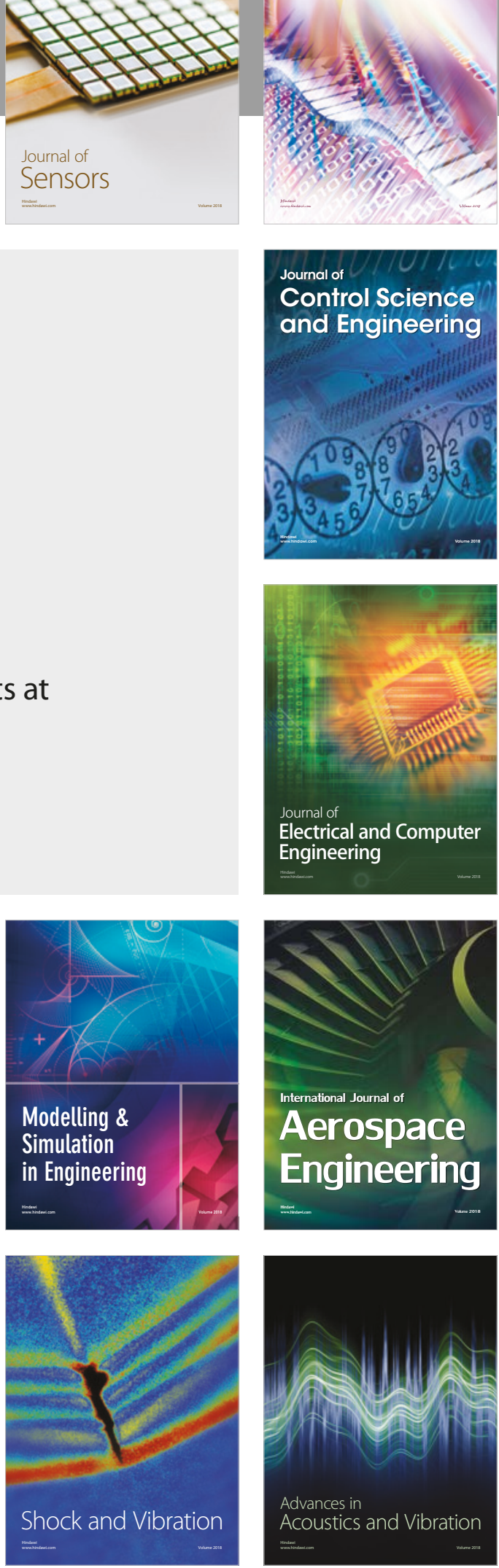